Sally A. Weller*

\title{
The politicization of research methods, illustrated in the case of plant closures
}

https://doi.org/10.1515/zfw-2019-0017

Received: July 23, 2019; accepted March 31, 2020

\begin{abstract}
This paper contributes to building better methods in economic geography by examining the coevolution of theory, methodology, and should read methodology, and the practice of research methods with the policy context. The paper suggests that debates about how economic geography defines its theoretical and methodological boundaries have not been sufficiently cognizant of the effects of policy engagement. It posits that the politicized contemporary context is aligning research practices to policy constituencies, reshaping research questions, altering the criteria of research validity, increasing the division between qualitative and quantitative approaches, and solidifying divisions between different sub-branches of the discipline. This process is illustrated by way of a genealogy of studies of plant closures. The conclusion links these changes to questions about the future of the discipline.
\end{abstract}

\section{Introduction: Methodology, Theory, and Politics}

Economic geography's persistent debate about the theoretical and methodological breadth of the subdiscipline brings into view the diversity of worldviews, ontologies, epistemologies and theoretical assumptions informing the various branches of inquiry (Amin/Thrift 2000; Sheppard/Plummer 2007; Barnes/Sheppard 2010; Yeung 2019). The debate has focused on whether to accept the full range of available methodological approaches, or whether to exclude approaches deemed insufficiently geographical in content or overly rigid in their methodological prescriptions. The recent flaring of the dispute (Rosenman et al. 2019; Yeung 2019) underscores the persistence of tensions around methodological differences and highlights the absence of a robust set of criteria for adjudicating among approaches. A second, somewhat one-sided debate is concerned with the policy relevance of research and the extent to which the policy domain can or should influence academic research (Peck, 1999; Martin 2001). The consensus is that geography has not adequately engaged with, or influenced, public policy and that geographical work should do more to promote the good of society in the public sphere (Castree 2010).

The debate about methodology has for the most part been conducted independently of the discussion of policy relevance. Yet increasing policy engagement suggests that it is now the time to think more carefully about the implications of geography's engagement with policy for methodological debates and disciplinary coherence. This article will suggest that these associations are increasingly influential and that they are crucial to understanding the evolution of the discipline's methodological divisions. To that end, the article explores the coevolution of research approaches - worldviews, theories, research methodologies, and research practices - with changing policy and social contexts. It will suggest that policy engagement is blurring the line between academic and policy domains, reshaping research questions, increasing the division between qualitative and quantitative approaches, altering the criteria of research validity, and politicizing research in ways that solidify divisions between different subbranches of the discipline.

The presentation proceeds as follows. The next section surveys debates about disciplinary evolution, focusing on the idea of engaged pluralism. It suggests suggests that the disciplinary debate has been blind to the influence of context and policy. Section three argues that policy engagement is politicizing research practices and proposes viewing the interactions of methodology, policy and context as a process of coevolution. Section four illustrates this process in the case of research on plant closures. The concluding section reflects on how policy engagement is reshaping economic geography.

*Corresponding author: Sally A. Weller, University of South Australia Business School, City West Campus, Adelaide 5000, Australia, Email: sally.weller@unisa.edu.au, 


\section{Pluralism and Disciplinary Methodology}

In contrast to disciplines like economics and anthropology, economic geographers have "never settled on a canonical methodology, set of techniques, list of venerated luminaries, disciplinary problematic, or definitive definitions” (Barnes/Sheppard 2010, 200). Rather, economic geography is "an evolving and pluralist project" characterized by its theoretical and methodological diversity (Mackinnon et al. 2009, 129). ${ }^{1}$ This diversity has at times prompted the accusation that geography lacks disciplinary discipline (Dorling/Shaw 2002), has frequently generated heated debate, and has spurred numerous attempts to limit the range of admissible ideas and approaches (see Barnes/Sheppard 2010). This section critically examines the accepted wisdom that economic geography's strength is its 'decentered' and pluralistic nature.

Sheppard and Plummer's $(2007,2545)$ "engaged pluralism" imagines a discipline open to ideas: "By engaged, we mean an open-ended attempt to learn about and learn from other approaches. By pluralism, we mean rejecting monism: the taken-for-granted idea that such engagement must result in a consensus about the best approach to a particular problem-that debates have to be resolved in favor of one position or another (or an agreed compromise)." This position seeks to unify the discipline by making a virtue of its methodological diversity and willingness to draw in knowledge from other social science disciplines (see also Peck 2012; Bathelt/Glücker 2018). Pluralism admits a diversity of worldviews and methodologies and welcomes the open interaction of multiple perspectives. Barnes and Sheppard (2010) draw on Dewey's pragmatic philosophy and Mouffe's agnostic democracy to advocate the 'trading' of knowledge among perspectives; a process they see as encouraging the learning that will generate the new knowledge essential to a vibrant discipline. They envisage a process wherein discussion, critique and more careful listening will promote a "politics of difference rather than of consensus or popularity" (Barnes/Sheppard 2010, 193). There are many examples in which engaging with ideas from other disciplines has enriched economic geography, as demonstrated by Harvey's (1989) spatialization of Marx or Jessop's (2001) reworking of regulation theory. However, Barnes and Sheppard (2010: 194) warn

1 Following Hoggett et al. (2014) methodology is taken to encompass epistemologies and ontologies, research design, methods and research practices, while methods applies narrowly to data collection strategies and technologies. against "glib superficial poaching" from other disciplines (on this, see Mackinnon et al. 2009).

Barnes and Sheppard $(2010,193)$ draw on Longino (2002) to describe the normative conditions that would enable the discipline to practice engaged pluralism. To paraphrase, these shared rules involve: (1) establishing publicly recognized forums for debate; (2) agreeing that critiques must be recognized and responded to; (3) acknowledging 'publicly recognized' standards for evaluating knowledge claims; and (4) maintaining 'equality of intellectual authority' among the debate's participants. They discuss some of the difficulties in achieving these conditions, not the least of which is the persistence of inequalities of power and influence. They lament that in practice geography seems to have produced a fragmented form of pluralism which has "created isolation, producing monologues rather than conversation", but still reiterate the call for pluralistic engagement. The problem, as they see it, is not with the theory but with failures of enactment.

There are at least four grounds for doubting that conclusion. The first is recognizing that pluralism is itself an ontological position - "the philosophical position that the ultimate reality of the universe consists of a plurality of entities" (Dow 1997, np) - a view that anti-essentialist perspectives would find incomprehensible. Before trading among positions is possible, subgroups within geography must first be imagined as separate entities, with relatively fixed positions, definitions, categories and boundaries to distinguish them from each other and from other disciplines. This only makes sense if knowledge is organized around identifiable intellectual frameworks (i.e. the 'isms' of Neoclassical, Marxian, Keynesian, Institutional, Foucauldian, Hayekian).

Second, the idea that there could be a standard for evaluating knowledge claims is problematic. Different intellectual frameworks are characterized by fundamental ontological and epistemological differences and are self-authenticating to the extent that each framework sets its own criteria by which truth is judged. It is difficult - if not impossible - to imagine how an agreed standard for evaluating knowledge claims could be identified (Boltanski and Thévenot 2006). For the trading of ideas to work in practice, protagonists holding different viewpoints would need to have enough common understanding to communicate with one another. Perhaps trading could be facilitated by 'hybrid' bridging concepts (Mackinnon et al. (2009) use the example of 'lock in') but that does not overcome the problem that the same word means different things depending on the theoretical framing. As the example of neoliberalization demonstrates, hybrid concepts do drive theoretical debate but do not necessarily 
improve the quality of explanation (Weller/O'Neill 2014). An added concern is that whilst geographers often nod to the work of major social theoreticians, the ontological and epistemological underpinnings of received theory are rarely discussed (Peck 2012). Incomplete knowledge of the wider frameworks risks the creation of incoherent hybridizations. If consistency across ontology, epistemology, theory and the nuances of research practice is the linchpin of within-approach research validity, then eclecticism is a threat to the integrity of research.

Third, pluralism and the trading metaphor have uncomfortable affinities with neoclassical economic thinking. In a market for ideas, the normative conditions for trading function, as in other markets, as rules governing who and what is admissible and which ideas are valued. By assuming all participants in the market contribute on an equal basis, the trading metaphor ignores the uneven politics of knowledge production and overlooks the reality of a discipline riddled with power inequities. For Rosenman et al. (2019), therefore, the notion of plurality is insufficient because acknowledging the existence of different perspectives does nothing the disrupt the power relations that privilege established perspectives. Smith's $(2005,896)$ withering critique equates pluralism with anti-geographical 'flat-earth' thinking. For Smith (2005, 892), engaged pluralism is a mirage ("gatekeeper anti-gatekeepering") that works to reinforce established institutional hierarchies.

Fourth, the expectation that pluralism could maintain vibrant interactions without collapsing into a single orthodoxy (i.e. monism) is difficult to reconcile with contemporary geographical understandings of learning and innovation. For pluralism to reproduce diversity would require that knowledge innovations are understood as analogous to product innovations, with each theoretical perspective eagerly incorporating the latest technology into its product. This commodification is contradicted by interaction- and practice-based understandings of learning and knowledge production. From a community of practice perspective, for example, disciplinary knowledge would advance through learning processes grounded in Habermassian communicative interaction and viewpoints would tend to converge (Habermas 1991, Wenger 1999). Social processes within any community encourage conformity to its sanctioned ideas and practices. In an academic community, that process is formalized by the academic peer review process and university recruitment traditions. Over time, converging worldviews would be expected to increase disciplinary coherence. ${ }^{2}$ Learning in

2 A worldview includes ideology, theory, discourse morality, ontology and epistemology (Wenger 1999). communities of practice involves the evolution of definitions, categories and problematizations as relationships, network configurations, contexts and dominant understandings change. Viewpoints converge as all contributors' views transform, gradually, and through processes of hybridization and redefinition, in an open and unbounded process. However, the process simultaneously marginalizes and excludes non-conforming views - at outcome that neatly explains geography's fragmented tribalism (Barnes and Sheppard 2010).

Finally - and the crucial issue for this paper - is that the notion of engaged pluralism creates the false impression of an academic debate insulated from the challenges and struggles of the lived world. The 'engagement' component, as defined by Sheppard and Plummer (2007), is confined to a forum of qualified speakers within the academic trading community. The rules of admission to the knowledge market, and its valuations based on theoretical merit, limit the capacity of outsiders - policy actors or other non-academic interests - to influence the discussion and to conjure an impermeable boundary between the academic and policy worlds. The communities of practice metaphor, in contrast, sees interaction with other disciplines and policy worlds as unavoidably exerting a direct influence on the discipline's development via network-based learning processes. ${ }^{3}$ From its perspective, economic geography's academic communities would be expected to coevolve organically, not only in conjunction with developments in other social sciences but also through their interactions with the policy domain and in response to changes in real world contexts.

\section{Policy Engagement as a Source of Division}

Pragmatic thinking has also influenced the world of policy. In the policy world pragmatism signals practicality over principle, about 'getting things done' in a way that signals responsiveness to the changing environment (Tavits, 2007). This resonates with geography's emphasis on context, but it also bends the criterion of truth toward practical efficacy. The effect, this section suggests, is to divide policy-engaged research.

In the twenty years since Peck (1999) explored the dilemmas of policy-related engagement, it is now routine

3 For example, relational economic geography resonates with relational and network-oriented research in sociology and business studies (e. g. Bathelt/Glücker 2018). 
for geographers to interact with the policy world and to at least aspire to "follow(ing) our investigations through to their implications for possible policy intervention and action - as an instigator of change, as an activist endeavour' (Martin 2001:203). However, the impact of policy engagement, and its implications, depend on the nature of that engagement. Much has changed since Massey (2001) complained that geography was 'endlessly ignored' by policy. At that time geographers saw the policy world as an audience for geographical insights or as a client for commissioned research; in both cases, as a relatively passive consumer of academic outputs. Since then, the changing roles and expectations of universities has transformed the relationship between the academic and policy worlds. In the contemporary context, policy constituencies are likely to be positioned as prosumers and coproducers rather than clients of academic research. This makes the perennial question of "What Kind of Geography for What Kind of Public Policy?" (Harvey 1974) more pertinent than ever. This section views these new forms of policy engagement as a source of division in economic geography.

Before outlining this division, it is important to note the dramatic changes, over the last thirty years, in the social context in which research takes place. The marketisation of the economy, the economization of society, the retrenchment of social services, the rise of financialization, and the individualization of responsibility for life events are well-documented, as is the resultant social fragmentation and rising inequality. The policy world in advanced economies has (unevenly) embraced a raft of innovations: the localized governance of policy problems, evidence-based policy, and the emergence of 'what works' in practice as the central criterion of policy assessment. As with the development of pluralism in economic geography, pragmatistic philosophies have provided influential justifications for these changes (although here informed by Rorty rather than Dewey). Like pluralism's trading, stakeholder-based governance assumes a level playing field of deliberative communication, which conceals the underlying power relationships that enable governance to work for government. Stakeholder-based governance arrangements bring research evidence into more direct alignment with partisan positions in political debates. These interactions are tending to split geography into two opposing camps: one researching for governments, the other for communities.

When the constituency is business or government-related policy networks, most engagement is formal, through commissioned consultancies or funded research partnerships. Here, since research designs respond to immediate real-world issues and problems, the research is often nar- rower in scope than research motivated by theoretical concerns. The central task is to generate the evidence required for managers to make decisions about available policy or strategic options, to defend and legitimize policy recommendations, or to evaluate policy experiments. Typically, a minimum requirement is that research provides policymakers with the numerical comparisons they require for allocating resources among places or groups. As a result, research designs used in policy contexts must be robust enough - as defined by the policy community - to weather politically-motivated criticism in the public domain. Robustness in this context means conforming to the policy world's accepted standards of research rigor, which typically demands clear definitions of terms, consistent meanings, testable hypotheses, the collection of quantitative data, and analysis in accordance with accepted standards of statistical sophistication (Sunley 1996). This is not the same criteria as applies to academic research, principally because policy critics are preoccupied with the representativeness of sampling but disinterested in the nuances of theoretical consistency (i.e. internal validity). In this type of policy research, qualitative methods are admissible when indicated by the research question, and when embedded in a multiple method approach, but are often dismissed when qualitative work stands alone (Glasmeier 2007). Policy constituencies abhor fuzzy thinking and scant evidence (Markusen 2003), but policy makers often lack the knowledge to distinguish between fuzzy thinking and theoretical sophistication, and often also lack the capacity to evaluate evidence critically. To manage this deficit, policymaker's judgements about research validity rely on rules of thumb. These include ranking methods hierarchically in a way that privileges experimental, quasi-experimental and then other quantitative designs, as well as favoring research recommendations consistent with both established narratives of best practice and the commonsense 'what works' insights drawn from practical administrative experience (Weller/Tierney, 2018). This process changes the criterion of external validity and has the effect of excluding findings that are inconsistent with established truths. The narrowing and targeting of research questions discourages large multi-method research programs. Triangulation among methods - once the recommended standard of validity (Sayer, 1992) - is diminished by the 'what works' validity test. It is replaced in stakeholder governance by a politicized form of triangulation as different stakeholders sponsor evidence to support their position.

In recent times, policy-oriented research has become entangled with - and possibly compromised by - associations with the 'what works' world of policy-led evidence. 
This describes contexts where the purpose of research is to provide justification for already-formed policy directions (Marston/Watts 2003). In the stakeholder-based governance arrangements dominating contemporary social policy, a process of sequential reflexive development of problems and solutions tends to narrow research questions and to require research evidence focused on the assessment of feasible policy responses (Bacchi 2009). The narrowing process does not aspire to solve social problems, as in the old command-and-control era of government intervention, but instead uses evidence to refine and rework a problem's parameters. When answers are foreshadowed by the framing of the questions, the evidence becomes increasingly 'policy-led'. Whilst stakeholder-based governance arrangements could be viewed as pooling perspectives to identify novel means to tackle complex problems (as in pluralistic trading), in practice only the views of experts who are 'on the same page' as policy leaders win a seat at the table. Here well-meaning academics sometimes replace community activists, adding to the marginalization of community voices (Weller 2019).

These developments manifest in research questions designed to confirm - rather than to critically interrogate - already available answers (Bathelt et al. 2017). It also increases pressure for research designs to fit a policy-defined version of the context; for example, by basing analyses on administrative regions rather than lived places or designing indexes of resilience rather than crafting assessments of place-based disadvantage. A policy-led context encourages the pragmatic mixing of methods, as required by the nature of the problem at hand and the preferred response options (Tashakkkori/Teddle 2003), but in a way that risks disarticulating data collection methods from their grounding in theoretical and methodological frameworks. By this means policy imperatives can encourage unethical research practices, such as manipulating territorial aggregations to erase 'hotspots' of disadvantage (Weller/Tierney 2018) or increasing an anticipated rate of change to emphasize the urgency of the need for policy action (Harrison 2010). Here pragmatic thinking equates what is 'true' with 'what works' for policy stakeholders (which, as austerity demonstrates, is not necessarily consistent with the common good).

Conversely, research might engage with policy by serving and working with activist networks and community groups: constituencies that are often excluded from the expert networks of stakeholder-based governance. This typically unfunded or modestly funded work is likely to be small-scale, perhaps involving a sole researcher or graduate student. Here too influencing policy is an explicit objective, in addition to theoretical motivations, with the objective of bringing alternative life-worlds into view so they can 'count' in the policy world. This type of research pursues topics and crafts research questions that are meaningful to its constituency, rather than to policymakers, and endeavors to generate knowledge resources for and with constituencies (Chatterton et al. 2008). Epistemologically, research in this space recognizes the indivisibility of knowledge and power and rejects the proposition that research can ever assess anything objectively or dispassionately: 'truth' is always specific to a context and to the standpoint from which that context is evaluated. Ontologically, it insists that theories and ideologies are crafted through, expressed in, and inseparable from, lived practice. This research tends to be practice-based, interpretivist and constructivist; it rejects the (critical realist) separation of the lived world from theorizations of it. Since the fashioning of research questions is governed by the needs of constituencies and potential end-users, contributing to academic debates often becomes a secondary concern (e. g. Derickson/Routledge 2015). This research is almost exclusively qualitative, with an emphasis on ethnographic or phenomenological methods and a focus on co-producing knowledge that can be useful in building alternative modes of living. Research is concerned with the relationships between the researcher and research sites and subjects, committed to emancipatory logics, and secure in the truth revealed by practices and emotions.

Engagement with these opposing constituencies and their very different politics and relationships to governmental power - divides the research community into opposing camps. The division here is not between qualitative and quantitative methods, or between 'shallow' and 'deep' research (Peck 1999) but extends to the scale of worldviews that encompass research approaches, methodologies and political allegiances. Yet despite their differences, the opposing policy alignments have much in common. They share a commitment to the reflexive coproduction of knowledge with lay collaborators, and in practice both provide evidence to support political agendas. In both, the generation of new evidence addresses problems and questions defined (at least initially) by policy partners in terms of their already-formed worldviews and priorities. In both, high-brow theory and meso-level explanation can fade from view. Glasmeier (2007) argued that research conducted for policy can also provide the foundations for community activism, but the politicization of research has reduced the plausibility of her argument. In the contemporary environment, researchers engaging with activists will be excluded from the policy process (see Beaumont et al. 2005); except for when the research is conducted for (and protected by) recognized expert think tanks (e.g. Rown- 
tree Foundation, Australia Institute). If repeated interactions contribute incrementally to converging understandings of the context and the policy problem, and academic researchers are drawn ever-closer to the policy networks that speak a compatible language, this division can only deepen over time.

In addition, the contemporary media-saturated context creates new challenges for data collection. Increasing sensitivity to privacy and disclosure (and stricter research Ethics protocols) make it harder to gain access to research sites. As discourses play a more important role in shaping events and understandings of events (Eldon/Crampton 2007), they also create vexing practical challenges for research. In the case of policy experts, intensified scrutiny and surveillance of their utterances discourages criticism of policy or of politicians, with the result that 'close dialogue' (Clark 1998) has been replaced by carefully crafted defensive narratives that barely deviate from the official storyline. Informants' descriptions - whether of government policies or firm strategies - now reiterate media releases but offer little additional information. Policy informants trained in customer service now recount a relentless series of success stories, are ever more artful in dodging inquisitive probes, and never expand on policy failures. The narrowing of research questions and localization of research fuels the perennial problem of informants attributing events to their own or some related local agency, oblivious to the macro-scale forces shaping local outcomes (Weller, 2014). Interviewees are increasingly self-aware, often rehearsing the stylized facts of policy scripts or echoing blogged stories of personal heroism. For survey-based research, privacy concerns and the shift to mobile phones inhibit access to respondents and increase research costs. The normalization of unethical push-polling survey practices and non-random sampling undermine the perceived quality and validity of survey data.

The next section uses the case of plant closures to show how these challenges are pushing qualitative research towards more ethnographic forms of engagement at the same time as they encourage quantitative research to more abstract and more mathematical formats.

\section{Policy's Influence in Research on Plant Closures}

Perhaps the most important aspect of policy's increasing influence over academic research is the capacity of policy managers to shop around for researchers that fit with their understanding of the problem and the set of possible inter- ventions. Analogous to the power of lead firms to govern their suppliers in other industries, universities redirect their supply effort to in-demand specializations. This demand and supply relationships is based on an imbalance in power. Consequently, increasing policy engagement, a changing research environment and disciplinary divisions are tangled up together in a co-evolution of theory, method and policy. This process can be illustrated by examining the detail of the evolution of changes in a specific field of study, research on plant closures. Plant closures are points of crisis that trigger rapid changes in local labor markets and local economies and link placebased unemployment and disadvantage to wider issues of deindustrialization and globalization. Since this area of research generates a wide range of research questions that span academic disciplines - economics, sociology, policy studies, labor studies, regional studies, urban studies and health sciences - it is an informative site for the study of interdisciplinary exchange. Since plant closures are the subject of intense policy and political interest, they also illuminate the changing relationship between research and policy. There are also practical reasons for the selection of this case: the account draws on the author's longterm engagement with plant closure research and policy in the Australian context.

The changing nature of plant closure research reveals how shifts in the framing of research questions - from descriptive and explicative to interpretative and prescriptive - foreshadow changes in the disciplinary focus of research, its theoretical framing, and the selection of research methods. This section's genealogy suggests that the coevolution of theory, method and policy on plant closures has comprised four distinct phases. In the 1980s, industrial geographies contextualized plant closures in firm and industry restructuring. The 1990s was an era of detailed studies of the impacts of plant closures on individual workers' employment prospects. In the 2000s, interest shifted to workers' psychological wellbeing. Then, over the last ten years, the research effort has bifurcated into either intensive ethnographic work on the emotional and social toll of job loss, or extensive 'big data' examinations of the inter-industry and inter-place mobility of decontextualized workers. Each phase develops in response to its predecessor and through complex interactions of policy, theory and context.

In the 1980s, studies of plant closure in industrial geography provided rich descriptive accounts of firm and labour restructuring and the resulting spatial redistributions of work and workers. These studies responded to the changes occurring in the observable world as the UK coal and steel industries began closing down and as manufac- 
turing jobs moved to low wage locations (Hudson/Sadler 1983; Massey 1984). Massey and Meegan (1982) epitomized the geographical approach when they insisted that the 'where' of job loss could not be understood independently of the 'who', 'how' and 'why'. These accounts relied on a combination of desk research, interviews and analysis of the aggregate data then available from government statistical agencies. The forms of analysis followed the established disciplinary traditions of industrial geography, deploying theories of industrial location, shift-share analysis and Gini coefficients. Although the analysis was relatively unsophisticated (this pre-dated personal computing), it was very much attuned to the macroscale forces producing local outcomes. This research effort, which was positioned outside the (then Thatcherite) policy tent, generated undeniable evidence of the poor outcomes experienced by affected workforces. That this evidence was ignored by policymakers (Massey 2001) was in part a consequence of the difficulty translating its explanations, which typically viewed outcomes as inevitably produced by the spatial workings of market capitalism, into feasible policy action. These accounts were also criticized within the academy, as post-structuralist ideas gained ascendancy, for being essentialist, deterministic, overly structural, too willing to deny local agency, and too focused on the world of working men. The tradition continues - albiet in ways that endeavor to respond to the earlier critiques in contemporary geographical political economies of plant closure (e. g. Pike 2005).

The second phase, from the mid-1980s, zeroed in on the microscale of the impacts of job loss for individuals, households and communities. This localization was stimulated by the pressing social problems associated with deindustrialization and the accompanying increase in long-term unemployment across the advanced economies. By this time policymakers had accepted that market processes were not resolving the unemployment crisis. In response, governments commissioned major research projects (e. g. Gallie et al. 1994) - to better understand the problem and to evaluate the existing suite of policy interventions (principally retraining programs and wage subsidies). These research projects were typically large and multi-method, collecting both qualitative and quantitative data, but using the qualitative material mainly to support and flesh out causal pathways identified through analysis of patterns in quantitative (survey) findings. Most studies were informed by Sayer's (1992) realist understanding of social science methodology and enabled by the advent of personal computing and the SPSS package. The focus was still on men and manufacturing. As these projects traced worker outcomes after plant closure, they initially treated the process as a simple before-and-after equation. Workers were expected to move (or not) from one permanent job to another similar permanent job. The cost of job loss depended on the duration of the gap between jobs. As the research developed, and drew in the role of cultures, regulations and institutions in creating the labour market's 'stickiness', explanations became more locally focused and more sophisticated, moving from dual labour market theories, to segmented labour markets, to differentiated labour markets (Rubery/Wilkinson 1994). This work reiterated, with remarkable inter-location consistency, the obvious fact that job losers find it harder to find new work when they live in places where jobs are scarce. In addition to place-based differences in opportunities, the differentiating impacts of age, gender, skill, and class figured prominently in explanations of employment outcomes (e.g. Gallie et al. 1994; Hanson/Pratt 1991; Weller/Webber 1998). This stream of research continues - for example in Weller (2008) - and responds to wider trends in the discipline: it is sensitive to process, views worker outcomes as trajectories, and directs more attention to accompanying regional policy interventions. When this type of research is commissioned by government, it is now more oriented than in the past to identifying best practice policy interventions able to be 'rolled out' in other locations. This development produces dilemmas for geographers aware of the place specific nature of social change and the unintended transformations accompanying policy mobilities.

As the number of empirical studies accumulated, three policy lessons emerged. The first was that labour market outcomes shaped by location, gender, ethnicity, age and class position are not amenable to 'quick fix' policy manipulation, at least not in the short term; a discouraging result for policymakers in search of 'what works' solutions. Second, the research was developing as a source of political opposition and critique of government policies, and as such was becoming an annoyance for policymakers. Third, it became evident from the research findings that retraining programs - the official response to structural adjustment crises - seldom made a significant difference to worker outcomes (Martin/Grubb 2001). Although this outcome reflects the over-riding power of employer preferences (for skilled, young, white, male workers), and the poor quality of some training programs, in practice it inadvertently provided evidential support for a shift from (Keynesian) intervention to (Neoliberal) 'work first' policies. The workfare perspective interpreted evidence of poor work prospects among displaced older working-class men as a reflection of individual deficits, such as lack of motivation or adaptability, rather than as being the consequence of a lack of job opportunities. 
In the third phase of research, these individual deficits became the object of policy in research on the mental health or wellbeing of job losers. This reorientation could be understood as a response to the observation in the earlier research that the poorest outcomes were associated with mental health problems. However, the shift can be more reliably explained as a part of a wider shift in the policy context associated with the individualization of responsibility for life events (Beck 1992), the shift to work-first policies, and changes in recruitment processes associated with the rise of human resource management. As a part of the same change in worldview and policy, trade union influence over (re)training policy settings declined (Machin 2000) and universities began replacing Industrial Relations and Labor Studies departments with psychology-oriented Human Resource Management specializations (Hanson 1991). Policymakers now preferred to fund research programs in the community health or preventative medicine disciplines focused on assessing the psychological traits of displaced workers and the capacity of individuals to respond positively to adverse events. This research has in general been more technically sophisticated than the earlier labour market studies, often including quasi-experimental designs, validated measures of mental health or wellbeing, and techniques of statistical analysis borrowed from medical research (e. g. Cox regression). This research operates in a positivist framework and does not require the support of subjective qualitative evidence. Extending a medical metaphor, the months after retrenchment were now understood as a 'recovery' period, comparable to physical recovery after an illness (e.g. Caplan et al. 1989; Price et al. 2002). The effect is to pathologize negative worker outcomes.

The political implications of this change are clear. Once the key outcome is mental health, the definition of positive worker outcomes no longer necessarily involves any return to the labour market. A positive outcome is, at the minimum, simply acceptance of a new reality. This shift was attractive to policymakers because it enabled non-employment outcomes - such as forced early retirement - to be counted as successful adjustments to changed circumstances. The shift is also attractive to policymakers because it provides them with actionable policy recommendations in the form of 'positive psychology' interventions designed to improve worker motivation and outlook (e. g. Zikic/Klehe 2006). Furthermore, this agenda resonates with a wider policy appetite for new forms of behavioral governance that seek to nudge individuals to make better choices (Thaler/Sunstein 2009). Workers who have participated in positive psychology interventions are likely to provide researchers with optimistic affirmations of the marketability of their individual human capital: accounts that contrast starkly to the tales of woe elicited in similar research in the 1980s. Yet the objective circumstances of retrenched workers in 1989 and 2019 are not all that dissimilar. The new approach obliterates awareness of labour market conditions, devalues embodied differences among workers, and diverts attention from the dearth of suitable jobs in affected locations.

The policy approach to assessing impacts for affected communities also changed as policymakers became more conscious of the effects of place reputation on local development. This awareness translated into the imperative to 'talk up' deindustrializing locations with a view to generating the entrepreneurial local identity considered necessary to attracting new job creating investment. Accordingly, examples of workers' better choices are now packaged in well-publicized post-retrenchment best-practice success stories with the aim of helping to stimulate market-led recovery. This new framing resonates with the crisis orientation of marketised governance, where the policy problem is understood as being to manage the crisis of plant closure while leaving market forces to manage labour market effects. This reframing sidelines consideration of the ways that institutions and regulatory frameworks in places generate differentiated opportunity structures for displaced workers and divorces the costs of plant closure for workers from wider issues of unemployment, deindustrialization and global shifts in production. This work continues, now often integrated into the resilience thinking of sociotechnical transition studies wherein workers 'adapt' rather than 'adjust' to social change.

It is important to stress here that the policy preference for positive framings of the post-retrenchment change process does not arise from careful consideration of the findings of previous research. The assumption of recovery has never been proven in quantitative studies and is routinely refuted in qualitative studies. The rule of thumb in Australia, based on the evidence of past research, is that a third of retrenched workers will continue their established careers, a third will be relegated to less skilled, less wellpaid and precarious positions, and a third - mostly those over 50 years old - will never work again. The proportions of workers arriving at these different destinations are conditioned by the place and timing of closure, the regulatory context, and the management of the process - for example, whether there is early notice of closure, redundancy payouts, and assistance with job search (see Weller/ Webber 1998). The assumption that 'resilient' workers will 'recover' resonates with the crisis-management imperatives of contemporary policy, but it stands as an imped- 
iment to developing better explanations of how, why, where and when workers' trajectories change.

In the final phase of development, new research again recalibrates questions and approaches, in large part in reaction to the previous phase. Interview data containing repeated renditions of the positive psychology resilience script is unconvincing when read in conjunction with objective evidence of declines in workers' employment, housing and income security. This disjuncture encourages delving behind the rehearsed scripts through deeper forms of engagement, and prompts the search for more reliable evidence, for example, from historical records. On the one hand, therefore, there is a reinvigoration of interest in intensive qualitative research, especially ethnographic work on the lived experience of unemployment and job loss (e. g. Berlant 2011; Beer 2018). This work returns to the long-standing sociological project of exposing the negative impacts of unemployment and underemployment but now with a focus on workers' increasing precariousness. This strategy is especially relevant in the austerity context of minimum government intervention, in research exploring the range of coping strategies impoverished people develop to navigate their everyday world. The work brings out - in ways not possible by the previous research approaches - how these personal strategies are shaped by moral economies of responsibility to families and communities. This stream aligns with the plight of working people, showing how survival strategies often involve collective community actions developed in defiance of government interventions (which are often depicted as compounding rather than alleviating life's stresses). Here explanations are based on what is important to people, not on patterns in data, and the research aims to influence policy by making hardship visible and by contributing to political campaigns to change government policy priorities.

On the other hand, a set of new 'big data' quantitative studies return to industrial geography's focus on the structural questions of inter-industry and inter-location mobility. These studies use advanced computing technologies to crunch historical data containing records of individual destinations after job loss. These new studies pitch at the macroscale, where they are framed by the regional development 'related variety' literature, rather than by the individual focus of earlier plant closure studies (e.g. Eriksson et al.2017). Since the data these studies access has been collected for other purposes, it does not include the detailed personal information analyzed in earlier labour market or psychological studies. The complexity theories informing this approach disarticulate macroscale data patterns from the intentions of individual agents, so there is no demand for qualitative confirmation of observed correlations. The results of these studies are often consistent with the findings of previous detailed studies. However, since information on key factors is unavailable, they offer very little in terms of explanation. This can lead to reversals of previous causal explanations. ${ }^{4}$ Nonetheless, big data studies are attractive to policymakers because their causal inferences, however tenuous, provide evidential support for contemporary (neoliberal) policies that encourage worker mobility as the preferred means to mitigate regional inequality. In this final stage, then, the path of evolution of research forks in a way that reinforces the division between qualitative and quantitative approaches, polarizes the selected qualitative and quantitative methods, and deepens the division of research on the axis of whether the research is 'for people' or 'for government' policy constituencies. The branch committed to people and lived practice increasingly deploys intensive research methodologies sensitive to context and relational interaction. The branch serving policy is increasingly mathematical and abstracted from the lived world, often dedicated to legitimizing alreadyformed policy directions.

Across these reorientations, understandings of place, space, and scale are key points of contention. Ethnographic studies are usually located in the intimate places of day-to-day lives. Detailed studies of labour markets are focus at a neighborhood-scale, understanding place as an emotional association operationalized as a journey-towork area. Here local labour markets are tangible expressions of localized relationships between labour supply, labour demand, and regulatory frameworks. Studies of the psychology of displaced workers either ignore place entirely or include crude statistical measures of place disadvantage as covariates. Big data studies compare data over large territories, where the regional container is a policy construct unrelated to local labour conditions and divorced from the lives of working people. Large data quantitative studies also analyze industrial mobility around a fixed matrix of industries and occupations, while qualitative work appreciates that changes of definitions and content within industrial categories are a part of the change process.

4 For example, Eriksson et al. (2017) observe an association between mobility and better worker outcomes and recommend the mobilization of displaced workers. Grounded research observes the same correlation but adds the explanation that the most employable workers move to central places to take up quality jobs. Less able workers rarely relocate, as they have no job offer to accept, and for them relocation is likely to be detrimental given housing considerations (Weller 2009). 
These variants now coexist - following Massey's (1984) notion of layering - as competing ways of understanding the nature of the problem and the scope of potential policy interventions. In a pluralist world, it might be imagined that these different perspectives could be brought into conversation with one another, as contributions to the task of "grasp(ing) the complexity and messiness of the economy" (Karenjit and Siemiatycki 2014, 5). However, in practice these approaches co-exist, sometimes at the same time and place, without significant 'trade' or productive interaction. The learning anticipated by communication-based theories stalls not only because of the incompatible worldviews of researchers. It is also blocked by their different disciplinary allegiances and the power of policymakers to control the disciplinary alignment of research. Perhaps a current large multi-method research program on plant closures, of which the author is a part, will begin to change this pattern (Beer et al.2019). It is deploying multiple methods with the explicit intention of initiating discussions about the different insights produced with a view to bridging positions and integrating perspectives.

To sum up, examining a specific field of research, such as plant closures, exposes the role of policy in shaping research and reveals policy's influence to be much greater than is evident in theoretical discussions of policy engagement. Policy's understanding of plant closure is increasingly at odds with economic geography's interests in place and scale. Policy now views plant closures as one-off crises that require short-term management, rather than as windows revealing wider global processes. It wants quantitative evidence proving that policy interventions improve worker outcomes and is not much interested encouraging theoretically-informed academic enquiry into job quality, precariousness, or social exclusion. Nonetheless, this account shows that research and policy on plant closures have coevolved in response to one another and to changing understandings of how the world works.

\section{Conclusion: Disciplinary Implications}

This paper has contributed to the attempt of building better methods in economic geography by examining the coevolution of worldviews, theories, research practice and the policy context. Detailing the specifics of this process in respect of plant closure research has revealed how research questions respond to changes in material contexts, to evolving debates within academic disciplines, to the findings of previous research and to the policy world's framing of social problems. This brings into view the unavoidably political nature of research practice.

When contemporary research designed and conducted in conjunction with policy constituencies is policy-led, much of it is correctly labelled as shallow and inferior compared to theoretically informed academic research (Peck, 1999). However, even when research is motivated by 'deep' concerns, the politicization of the context has made it much more difficult to construct the sorts of explanations demanded, for example, by Yeung (2019). In the contemporary context, where policy and evidence are managed by political actors, frame-shifting questions about the foundational aspects of the context might never be asked. When pragmatic policy regimes encourage the undisciplined co-mingling of ideas from multiple theoretical lineages, it undermines the theoretical coherence of academic scholarship. The politicization of research - and the uneven power relations that govern research - stifles the possibility of constructive, reflexive academic debate.

Two observations follow. The first concerns geography's engagement with the lived world. There was a time when the recommended solution to geography's theory wars was to engage with the struggles of ordinary people (Smith, 2005). Now that research is politicized, and deeply implicated in the workings of state power, that advice no longer promises to steer the discipline toward a socially-optimal course. A conversation about how to manage policy engagement in a way that preserves economic geography's interests in place and space and maintains geography's critical edge therefore seems overdue.

The second concern is for the future of the subdiscipline. The changed research context makes the position of economic geography more perilous than implied by the threat of fragmentary pluralism (Barnes/Sheppard 2010). The changes in context - the increasing distance between what people do and what they say they do; the increasing complexity of the world and the blurring of the associations between causes, intentions, outcomes and effects; and the open politicization of research - threaten most the multi-method research informed by critical realist ontologies that was the hallmark of economic geographical research in the 1980s and 1990s (Sayer, 1992). The research approaches favored by the contemporary context - either ethnography or data mining - are already 'owned' by other disciplines: anthropology is the home of ethnography and economics is the home of abstract mathematical modelling. What space is there left for economic geography?

As a discipline, economic geography has rejected calls for a methodological unity. But the resort to pluralism is unconvincing. Without a unifying core, geography has no 
place from which to defend its critical perspectives and no means to retain its membership. A core that unites the discipline around an appreciation of the difference that space makes, or its 'geographical imagination' (Gregory 1994) cannot hold ground without some methodological boundaries to limit the encroachment of eclecticism and the drift to disciplines with a more defined methodology. The conclusion, therefore, is that nurturing methodological core might still be necessary for the survival of economic geography.

\section{References}

Amin, A./Thrift, N. (2000): What Kind of Economic Theory for What Kind of Economic Geography? In: Antipode, (32)1, 4-9.

Bacchi, C. (2009): Analysing policy: what's the problem represented to be? Pearson/Adelaide.

Bailey, D./Chapain, C./de Ruyter, A. (2012): Employment Outcomes and Plant Closure in a Post-Industrial City: An Analysis of the Labour Market Status of MG Rover Workers Three Years On. In: Urban Studies, (49)7, 1595-1612.

Barnes, T./Sheppard, E. (2010): 'Nothing Includes Everything': Towards Engaged Pluralism in Anglophone Economic Geography. In: Progress in Human Geography, (34)2, 193-214.

Bathelt, H./Coe, N./Kerr, W./Robert-Nicoud, F. (2017): Editorial: Economic Geography IMPULSES. In: Journal of Economic Geography, (17), 927-933.

Bathelt, H./Glückler, J. (2018): Relational Research Design in Economic Geography. In: Clark, G./Feldman, M./Gertler, M./Wójcik, D. (eds) The New Oxford Handbook of Economic Geography. Oxford University Press/Oxford, 1-23.

Beaumont, J./Loopmans, M./Uitermark, J. (2005): Politicization of Research and the Relevance of Geography: Some Experiences and Reflections for an Ongoing Debate. In: Area, (37)2, 118-126.

Beck, U. (1992): The risk society: towards a new modernity. Sage/ Thousand Oaks CA.

Beer, A./Weller, S./Barnes, T./Onur, I./Ratcliffe, J./Bailey, D./ Sotarauta, M. (2019) The urban and regional impacts of plant closures: new methods and perspectives. In: Regional Studies, Regional Science, 6(1), 380-394.

Beer, S. (2018): Living the Cruel Futures of Industrial Change. In: Social \& Cultural Geography, (19)1, 102-119.

Berlant, L. (2011): Cruel optimism. Duke University Press/Durham NC.

Boltanski, L./Thévenot, L. (2006): On justification: Economies of worth. Princeton University Press/Princeton NJ.

Caplan, R./Vinokur, A./Price, R./Van Ryn, M. (1989): Job Seeking, Reemployment, and Mental Health: A Randomized Field Experiment in Coping with Job Loss. In: Journal of Applied Psychology, (74)5, 759-769.

Castree, N. (2010): The Point is to Change it: Geographies of Hope and Survival in an Age of Crisis. John Wiley \& Sons/New York.

Chatterton, P./Fuller, D./Routledge, P. (2008): Relating Action to Activism: Theoretical and Methodological Reflections. In: Kindron, S./Pain, R./Kesby, M. (eds) Participatory Action
Research Approaches and Methods: Connecting People, Participation and Place. Routledge/London, 216-22.

Clark, G. (1998): Stylized Facts and Close Dialogue: Methodology in Economic Geography. In: Annals of the Association of American Geographers, 88(1), 73-87.

Derickson, K.D./Routledge, P. (2015): Resourcing Scholar-Activism: Collaboration, Transformation, and the Production of Knowledge. In: The Professional Geographer, (67)1, 1-7.

Dorling, D./Shaw, M. (2002): Geographies of the Agenda: Public Policy, the Discipline and its (Re)'turns'. In: Progress in Human Geography, 26(5), 629-64.

Dow, S. (1997): Methodological pluralism and pluralism of method? In: Salanti, A./Screpanti, E. (eds) Pluralism in Economics: New Perspectives in History and Methodology. Edward Elgar/ Cheltenham, 89-99.

Elden, S./Crampton, J. (eds) (2007): Knowledge, space and power: Foucault and geography. Ashgate/London.

Eriksson, R./Hane-Weijman, E./Henning, M. (2017): Sectoral and Geographical Mobility of Workers after Large Establishment Cutbacks or Closures. In: Environment and Planning A: Economy and Space, (50)5, 1071-1091.

Gallie, D./Marsh, C./Vogler, C. (eds) (1994): Social change and the experience of unemployment. Oxford University Press/Oxford.

Glasmeier, A. (2007): Methodologies, Epistemologies, Audiences. In: Tickell, A./Sheppard, E./Peck J./Barnes T. Politics and Practice in Economic Geography. Sage/London, 210-220.

Habermas, J. (1991): Communication and the evolution of society. Polity Press/London.

Hanson, C. (1991): From Industrial Relations to Human Resource Management. In: Hanson, C. (ed.) Taming the Trade Unions. Palgrave Macmillan/London, 116-121.

Harrison, P. (2010): Valuing the Future: The Social Discount Rate in Cost-Benefit Analysis. Productivity Commission Visiting Research Paper. Productivity Commission/Canberra.

Harvey, D. (1974): What kind of geography for what kind of public policy?. In: Transactions of the Institute of British Geographers, (63), 18-24.

Harvey, D. (1989): The condition of modernity. Oxford University Press/Oxford.

Hoggett, K./Lees. d./Davies, A. (2014): Researching human geography. Routledge/London.

Hudson, R./Sadler, D. (1983): Region, Class, and the Politics of Steel Closures in the European Community. In: Environment and Planning D: Society and Space, (1)4, 405-427.

Jessop, B. (2001): Regulation theory and the crisis of capitalism. Edward Elgar Publishing/Cheltenham.

Karenjit C./Siemiatycki, E. (2014): Primacy or Pluralism: Future Directions in Economic Geography. In: The Professional Geographer, (66)1, 4-10.

Longino, H. (2002): The fate of knowledge. Princeton University Press/Princeton, NJ.

Machin, S. (2000): Union Decline in Britain. In: British Journal of Industrial Relations, (38)4, 631-645.

MacKinnon, D./Cumbers, A./Pike, A./Birch, K./McMaster, R. (2009): Evolution in Economic Geography: Institutions, Political Economy, and Adaptation. In: Economic Geography, (85)2, 129-150.

Markusen, A. (2003): Fuzzy Concepts, Scanty Evidence, Policy Distance: The Case for Rigour and Policy Relevance in Critical Regional Studies. In: Regional Studies, (37)6-7, 701-717. 
Marston, G./Watts, R. (2003): Tampering with the Evidence: A Critical Appraisal of Evidence-based Policy-making. In: The Drawing Board: An Australian Review of Public Affairs, (3)3, 143-163.

Martin, J./Grubb, D. (2001): What Works and for Whom: A Review of OECD Countries' Experiences with Active Labour Market Policies. In: Swedish Economic Policy Review, (8)2: 9-56.

Martin, R. (2001): Geography and Public Policy: The Case of the Missing Agenda. In: Progress in Human Geography, (25)2, 189-210.

Massey, D. (2001) Geography on the agenda. In: Progress in Human Geography, (25), 5-17.

Massey, D. (1984): Spatial divisions of labour: Social structures and the geography of production. Macmillan/Basingstoke.

Massey, D./Meegan, R. (1982): The anatomy of job loss: The how why and where of employment decline. Methuen/London.

Peck, J. (2012): Economic Geography: Island Life. In: Dialogues in Human Geography, (2)2, 113-133.

Peck, J. (1999): Grey Geography? In: Transactions of the Institute of British Geographers, (24)1, 131-35.

Pike, A. (2005): Building a Geographical Political Economy of Closure: The Case of R\&D Co in North East England. In: Antipode, (37)1, 93-115.

Price, R./Choi, J./Vinokur, A. (2002): Links in the Chain of Adversity following Job Loss: How Financial Strain and Loss of Personal Control Lead to Depression, Impaired Functioning, and Poor Health. In: Journal of Occupational Health Psychology, (7)4, 302-312.

Rosenman, E./Loomis, J./Kay, K. (2019): Diversity, Representation, and the Limits of Engaged Pluralism in (Economic) Geography. In: Progress in Human Geography, DOI: 0309132519833453.

Rubery, J./Wilkinson, F. (eds.) (1994): Employer strategy and the labour market. Oxford University Press/Oxford.

Sayer, A. (1992): Method in social science: A realist approach. Routledge/London.

Sheppard, E./Plummer, P. (2007): Toward engaged pluralism in geographical debate. In: Environment and Planning A, (39), 2545-2548.

Smith, N. (2005): Neo-critical Geography, or, the Flat Pluralist World of Business Class. In: Antipode (37) 5, 887-899.
Sunley, P. (1996): Context in Economic Geography: The Relevance of Pragmatism. In: Progress in Human Geography, (20)3, 338-355.

Tashakkkori, A./Teddle, C. (2003): Handbook of mixed methods in social \& behavioural research. Sage/Thousand Oaks CA.

Tavits, M. (2007): Principle vs. pragmatism: Policy shifts and political competition. In: American Journal of Political Science, 51(1), 151-165.

Thaler, R./Sunstein, C. (2009): Nudge: Improving decisions about health, wealth, and happiness. Penguin/New York.

Weller, S. (2019): Dialectics of community and government. In: Campbell, A./Duffy, M./Edminson, B. (eds) Located Research: Regional places, transitions and challenges. Palgrave/London, 369-86.

Weller, S. (2014): Creativity or costs? Questioning the success of New Zealand fashion. In: Journal of Economic Geography, 14(4), 721-737.

Weller, S. A. (2009): Critical Events and Labour Mobility: Relocations in the Wake of the Ansett Airlines Collapse. In: Geographical Research, 47(3), 227-41.

Weller, S. (2008): Are labour markets necessarily 'Local'? Spatiality, segmentation and scale. In: Urban Studies, 45(11), 2203-2223.

Weller, S./O'Neill, P. (2014): An argument with neo-liberalism. In: Dialogues in Human Geography, 4(2), 105-130.

Weller, S./Tierney, J. (2018): Evidence in the networked governance of regional decarbonisation: a critical appraisal. In: Australian Journal of Public Administration, 77(2), 280-293.

Weller, S./Webber, M. (1999): Re-employment after retrenchment: evidence from the TCF Industry Study. In: Australian Economic Review, 32(2), 105-29.

Wenger, E. (1999): Communities of practice: Learning, meaning, and identity. Cambridge University Press/Cambridge.

Yeung, H. W-C. (2019): What Kind of Theory for What Kind of Human Geography? In: Dialogues in Human Geography, (9)3, 283-292.

Zikic, J./Klehe, U. (2006): Job loss as a blessing in disguise: The role of career exploration and career planning in predicting reemployment quality. In: Journal of Vocational Behavior, (69)3, 391-409. 